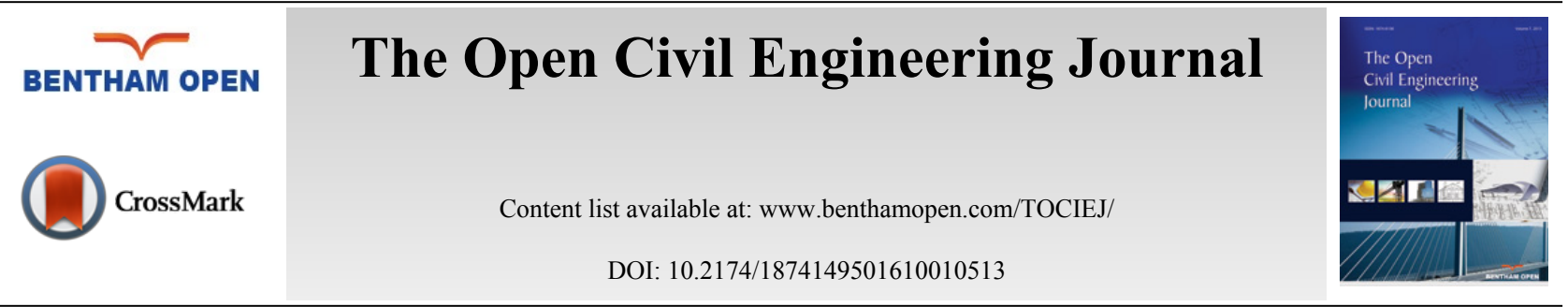

RESEARCH ARTICLE

\title{
Experimental Study on Relationship Between Mechanical, Seepage Characteristics and 3D Morphology Parameters of Marble Joint
}

\author{
Chenlin Wang ${ }^{1}$, Baohua Guo ${ }^{1,2,3, *}$ and Long Wang ${ }^{1}$ \\ ${ }^{I}$ School of Energy Science and Engineering, Henan Polytechnic University, Jiaozuo, 454000, Henan, PR, China \\ ${ }^{2}$ Key Laboratory of Safety and High-efficiency Coal Mining, Ministry of Education (Anhui University of Science and \\ Technology), Huainan, 232001, Anhui, PR, China \\ ${ }^{3}$ Collaborative Innovation Center of Coal Work Safety, Jiaozuo,454000, Henan, PR, China
}

Received: December 21, 2015

Revised: February 25, 2016

Accepted: April 4, 2016

\begin{abstract}
In order to investigate the influence of 3D morphology parameters of marble joint surface on its mechanical and seepage characteristics, artificial joints of coarse-grained marbles were scanned by Tianyuan OKIO-typed 3D laser scanner; and then, the professional software was used to obtain the 3D morphology parameters of marble joint surface. Tests of water flowing through a single joint were conducted under different normal stress and feeding water head by using self-developed radial flowing system, and the exponential function between flow rate per head and normal stress, the linear relation between equivalent hydraulic aperture and mechanical aperture, and the linear relation between joint closure and normal stress were obtained. The relationships between regression parameters in above three formulas and 3D morphology parameters of joint surface were also studied by fitting method. All in all, the results may provide a reference to understand the mechanical and seepage characteristics of rough rock joint.
\end{abstract}

Keywords: 3D morphology parameters, Mechanical and seepage characteristics, Rock mechanics, Rough joint surface.

\section{INTRODUCTION}

There are a lot of pores and joints in engineering rock mass, the destruction of rock mass is mainly caused by the crack opening and expanding. The deformation and failure of rock mass are controlled by the mechanical and seepage characteristics of rock joint; the morphology of joint surface is the important factor to influence the mechanical and seepage characteristics of rock joint. Therefore, quantitative description of joint surface morphology is one of the key works for studying the seepage-stress coupling mechanism of a rough single rock joint.

In recent years, many scholars have conducted the seepage-stress coupling tests for a single rock joint. Kranz et al., [1] experimentally studied on the permeability of the jointed Barre granites to show that the flow velocity has a power relation with the effective stress. Li and Tao [2] found that there may be a fractal relationship between flow rate per head and normal stress by analyzing the research results of Kranz et al., [1]. Su et al., [3] carried on the seepage-stress coupling test for artificial joint of concrete block and the formula is as follow:

$$
\ln (Q / \Delta H)=A+\frac{B}{1+C \sigma_{n}}
$$

where $A, B$ and $C$ are the regression parameters, $\sigma_{\mathrm{n}}$ is normal stress. Louis [4] found experimentally a negative exponential relationship between hydraulic conductivity and normal stress in a single rock joint. Jones [5] proposed an empirical formula of hydraulic conductivity of carbonate joint as follow:

\footnotetext{
* Address Corresponding to this author at the School of Energy Science and Engineering, Henan Polytechnic University, Jiaozuo, 454000, Henan, PR, China; Tel: +8613949669615; Email: guobaohua@139.com
} 


$$
K_{f}=K_{0}\left[\log \left(p_{h} / p\right)\right]^{3}
$$

Where $p$ is the normal stress, $p_{\mathrm{h}}$ is the normal stress when $K_{f}=0$. Nelson [6] proposed a power equation expressing the relation between permeability coefficient and normal stress for Navajo sandstone joint. Gale [7] put forward a linear equation expressing the relationship between hydraulic conductivity of rock joint $K_{f}$ and normal stress $\sigma_{\mathrm{n}}$ for three kinds of rock joints such as granite, marble and basalt in laboratory. Elliot et al., [8] discovered the linear relationship between the equivalent hydraulic aperture $e_{h}$ and the mechanical aperture $e_{m}$. In the view of Barton et al., [9], mechanical aperture is closed to the equivalent hydraulic aperture in smooth joint surface with a large aperture; the mechanical aperture is several times wider than the equivalent hydraulic aperture for rough rock joint; the hydraulic aperture is approximately linear with the JRC (Joint Roughness Coefficient); however, the nonlinear relationship becomes increasingly remarkable with the increase of JRC, the relationship between equivalent hydraulic aperture $b_{h}$ and mechanical aperture $b_{m}$ based on lots of experiments can be described as follow, which is suitable for $b_{m} \geq b_{h}$ :

$$
b_{h}=\frac{b_{m}^{2}}{J R C^{2.5}}
$$

Witherspoon et al., [10] summarized the linear relationship between equivalent hydraulic aperture $b_{h}$ and mechanical aperture $e_{m}$. Zimmerman and Bodvarsson [11] concluded that the dependence of equivalent hydraulic aperture to the ratio of average mechanical aperture to its standard deviation is less than that of mechanical aperture. Hakami [12] found that the ratios of the average mechanical aperture to hydraulic aperture are 1.1 1.7 for the mechanical aperture of joint with average of 100 500 $\mu \mathrm{m}$. Sun et al., [13] expressed the normal closure characteristics of rock joint by using an exponential function, While Goodman [14] expressed the normal closure characteristics of rock joint by using a hyperbolic function, which both indicated that the normal closure of rock joint will increase, however aperture of rock joint will decrease gradually with the increase of normal stress.

Above empirical formulas were obtained based on the seepage-stress coupling experiments of the rock joint in the field or in the laboratory, but most of them did not consider quantitatively or qualitatively the influence of joint roughness. Thus, this paper analyzed the relationship between flow rate per head and normal stress, equivalent hydraulic aperture and mechanical aperture, and joint closure and normal stress based on seepage-stress coupling tests for six white coarse-grained marble joints by using self-developed radial flowing system. Additionally, 3D morphology parameters of marble joint surface were used to analyze above three relationships by fitting the relationship between the parameters in above three formulas and some 3D morphology parameters.

\section{TEST PROCEDURES}

Six white coarse-grained marble samples with grain size of about $5 \mathrm{~mm}$ are prepared into standard specimens with the diameter of $50 \mathrm{~mm}$ and the height of $100 \mathrm{~mm}$, and then a blind hole with the length of $60 \mathrm{~mm}$ and diameter of $6 \mathrm{~mm}$ is drilled along the axis of each cylindrical sample. Tensile joints of coarse-grained specimens are made at the midpoint of the long axis by using self-made splitting mold as shown in Fig. (1). The splitting mold is consisted of two same parts, and each part includes an iron plate with a cylindrical groove and an iron wire with triangular section. There is a slot perpendicular to the axial direction in the iron plate at the midpoint of the long axis and the iron wire is fixed in the slot with an edge being used to split the sample.

Joint surfaces of coarse-grained marble specimens are scanned by Tianyuan OKIO-typed 3D laser scanner, in which CCD camera resolution is $1.44 \times 10^{6}$ pixel and the measurement accuracy is up to $20 \mu \mathrm{m}$. Because one time of scan is not complete to get all morphology data of the joint surface, mark points (the black rings on the surface, as shown in Fig. (1) are needed to control the splicing of scanning data. For example the scanned upper and lower parts of specimen M1 were processed by Geomagic Studio software as shown in Fig. (2) (Where M1-upper is the upper joint surface and M1-lower is the lower joint surface), in which the yellow circle was generated from the mark points on the surface of the sample. Meanwhile the scanned upper and lower rock joint surfaces of specimen M1 were processed by Geomagic Studio software as shown in Fig. (3). Then 3D morphology parameters of each joint surface are calculated by rock surface morphology test software and the results are as shown in Table 1, in which 3D morphology parameters include Maximum peak height of surface $S_{p}(m m)$, Maximum valley depth of surface $S_{m}(m m)$, Contour maximum height $\mathrm{S}_{\mathrm{h}}(\mathrm{mm})$, Central line average height $\mathrm{S}_{\mathrm{a}}(\mathrm{mm})$, Root mean square height $\mathrm{S}_{\mathrm{q}}(\mathrm{mm})$, Skewness $\mathrm{S}_{\mathrm{s}}$, Kurtosis $\mathrm{S}_{\mathrm{k}}$, Contour area ratio $S_{A}$, Root mean square slope $S_{d q}(m m)$, The peak average density $S_{d s}$. Additionally, the average values of 3D 
morphology parameters of upper and lower joint surfaces of each specimen are calculated as shown in Table $\mathbf{2}$.

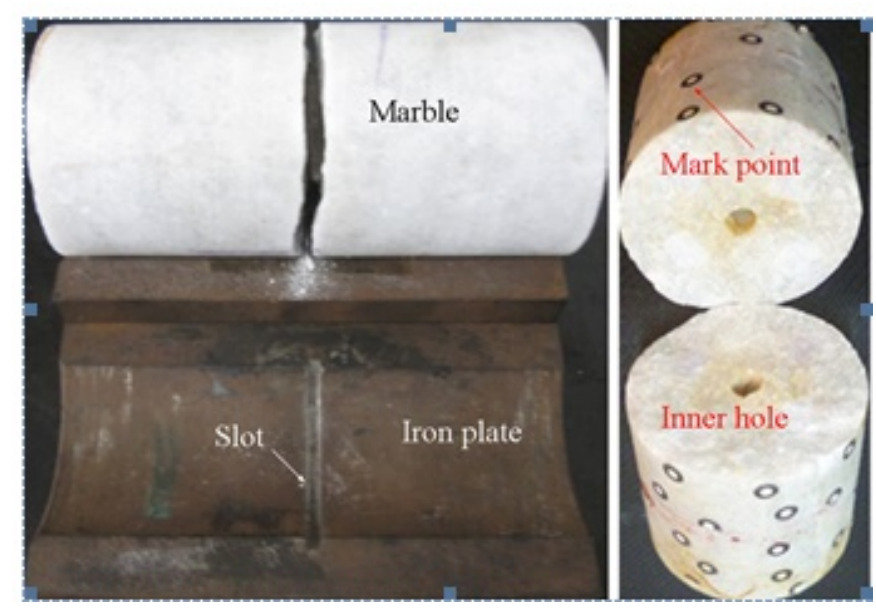

Fig. (1). Self-made splitting mold and joint surface.

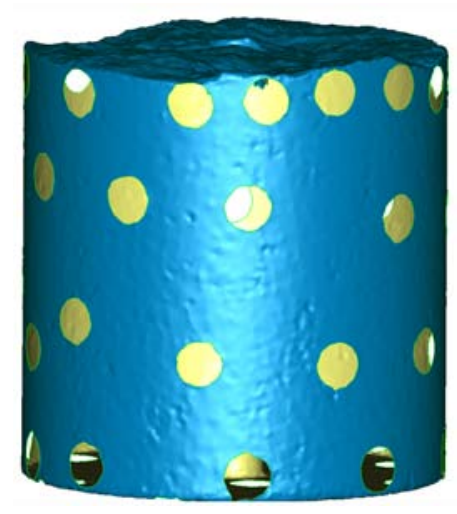

(a)M1-upper

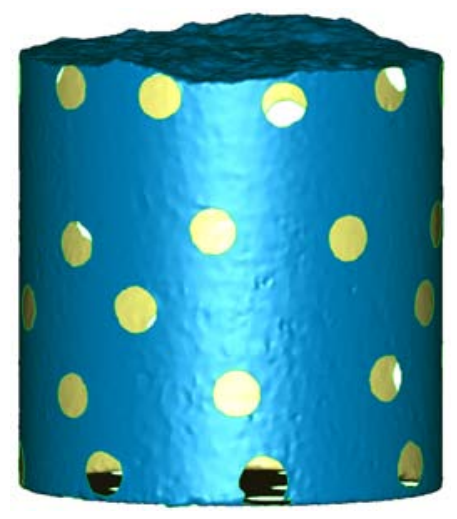

(b)M1-lower

Fig. (2). The scanned upper and lower part of specimen M1.

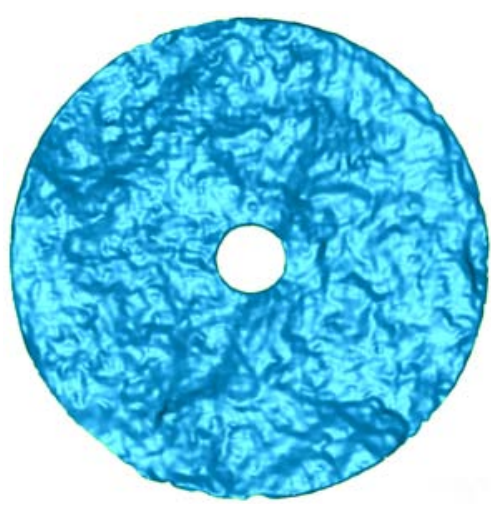

(a)M1-upper

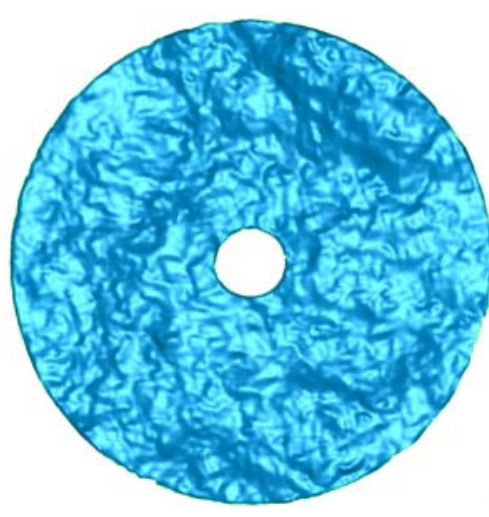

(b)M1-lower

Fig. (3). The scanned upper and lower joint surfaces of specimen M1. 
Table 1. 3D morphology parameters of joint surfaces.

\begin{tabular}{|c|c|c|c|c|c|c|c|c|c|c|}
\hline No. & $\mathbf{S}_{\mathbf{p}}(\mathbf{m m})$ & $\mathbf{S}_{\mathbf{m}}(\mathbf{m m})$ & $\mathbf{S}_{\mathbf{h}}(\mathbf{m m})$ & $\mathbf{S}_{\boldsymbol{a}}(\mathbf{m m})$ & $\mathbf{S}_{\mathbf{q}}(\mathbf{m m})$ & $\mathbf{S}_{\mathbf{s}}$ & $\mathbf{S}_{\mathbf{k}}$ & $\mathbf{S}_{\mathbf{A}}$ & $\mathbf{S}_{\mathrm{dq}}(\mathbf{m m})$ & $\mathbf{S}_{\mathrm{ds}} \times \mathbf{1 0} \mathbf{m}^{-3}$ \\
\hline M1-upper & 0.07 & -0.28 & 0.34 & 0.60 & 0.82 & 1.82 & 3.53 & 1.04 & 2.06 & 0.66 \\
M1-lower & 0.17 & -0.24 & 0.41 & 0.61 & 0.83 & -0.52 & 3.11 & 1.06 & 1.13 & 2.55 \\
\hline M2-upper & 0.22 & -0.30 & 0.53 & 0.28 & 0.41 & 0.59 & 3.97 & 1.04 & 0.59 & 6.35 \\
M2-lower & 0.13 & -0.37 & 0.50 & 0.31 & 0.44 & -0.43 & 3.87 & 1.04 & 0.57 & 0.63 \\
\hline M3-upper & 0.03 & -0.03 & 0.06 & 0.44 & 0.63 & 1.06 & 3.73 & 1.05 & 0.90 & 3.22 \\
M3-lower & 0.04 & -0.06 & 0.10 & 0.44 & 0.63 & -0.77 & 3.30 & 1.05 & 0.81 & 3.27 \\
\hline M4-upper & 0.20 & -0.41 & 0.61 & 0.33 & 0.50 & -0.90 & 5.05 & 1.04 & 0.81 & 3.40 \\
M4-lower & 0.20 & -0.53 & 0.73 & 0.33 & 0.50 & 1.00 & 5.60 & 1.04 & 1.15 & 2.55 \\
\hline M5-upper & 0.01 & -0.18 & 0.19 & 0.38 & 0.54 & -0.77 & 3.35 & 1.04 & 0.66 & 0.67 \\
M5-lower & 0.29 & -0.16 & 0.45 & 0.37 & 0.53 & 0.77 & 3.68 & 1.04 & 0.73 & 5.06 \\
\hline M6-upper & 0.05 & -0.15 & 0.20 & 0.43 & 0.61 & -0.29 & 5.89 & 1.05 & 0.88 & 3.16 \\
M6-lower & 0.55 & -0.09 & 0.65 & 0.44 & 0.63 & 0.24 & 3.31 & 1.05 & 0.64 & 3.81 \\
\hline
\end{tabular}

Table 2. The average values of 3D morphology parameters.

\begin{tabular}{|c|c|c|c|c|c|c|c|c|c|c|}
\hline No. & $\mathbf{S}_{\mathbf{p}}(\mathbf{m m})$ & $\mathbf{S}_{\mathbf{m}}(\mathbf{m m})$ & $\mathbf{S}_{\mathbf{h}}(\mathbf{m m})$ & $\mathbf{S}_{a}(\mathbf{m m})$ & $\mathbf{S}_{\mathbf{q}}(\mathbf{m m})$ & $\mathbf{S}_{\mathbf{s}}$ & $\mathbf{S}_{\mathbf{k}}$ & $\mathbf{S}_{\mathbf{A}}$ & $\mathbf{S}_{\mathrm{dq}}(\mathbf{m m})$ & $\mathbf{S}_{\mathrm{ds}} \times \mathbf{1 0}^{-3}$ \\
\hline M1 & 0.12 & -0.26 & 0.38 & 0.61 & 0.83 & 0.65 & 3.32 & 1.05 & 1.60 & 1.61 \\
\hline M2 & 0.18 & -0.34 & 0.52 & 0.30 & 0.43 & 0.08 & 3.92 & 1.04 & 0.58 & 3.49 \\
\hline M3 & 0.04 & -0.05 & 0.08 & 0.44 & 0.63 & 0.15 & 3.52 & 1.05 & 0.86 & 3.25 \\
\hline M4 & 0.2 & -0.47 & 0.67 & 0.33 & 0.5 & 0.0 & 5.33 & 1.04 & 0.98 & 2.98 \\
\hline M5 & 0.15 & -0.17 & 0.32 & 0.38 & 0.54 & 0 & 3.52 & 1.04 & 0.70 & 2.87 \\
\hline M6 & 0.3 & -0.12 & 0.43 & 0.44 & 0.62 & -0.03 & 4.6 & 1.05 & 0.76 & 3.49 \\
\hline
\end{tabular}

Self-developed radial flowing system for studying the seepage characteristics of single rock joint shown in Fig. (4), includes three parts: water supplying system, loading system, and water collecting system. Water head is controlled by the height of the water tank relative to the rock joint; loading system includes pressure head, upper plate, lower plate, rod, and dial indicator; collecting system mainly includes heat-shrinkable tube (collecting water outflow from rock joint), inlet tube, discharging tube, beaker and balance. The normal stress is calculated by the pump pressure and the section area of rock specimen, and the normal displacement is measured by three equidistant dial indicators which are installed to the rods which are fixed to upper plate. Measuring heads of three dial indicators touch the lower plate fixed to specimen. The reading variation of three dial indicators can reflect the normal displacement between upper plate and lower fixed plate, and it is taken as the normal deformation of rock joint approximately under lower normal stress levels.

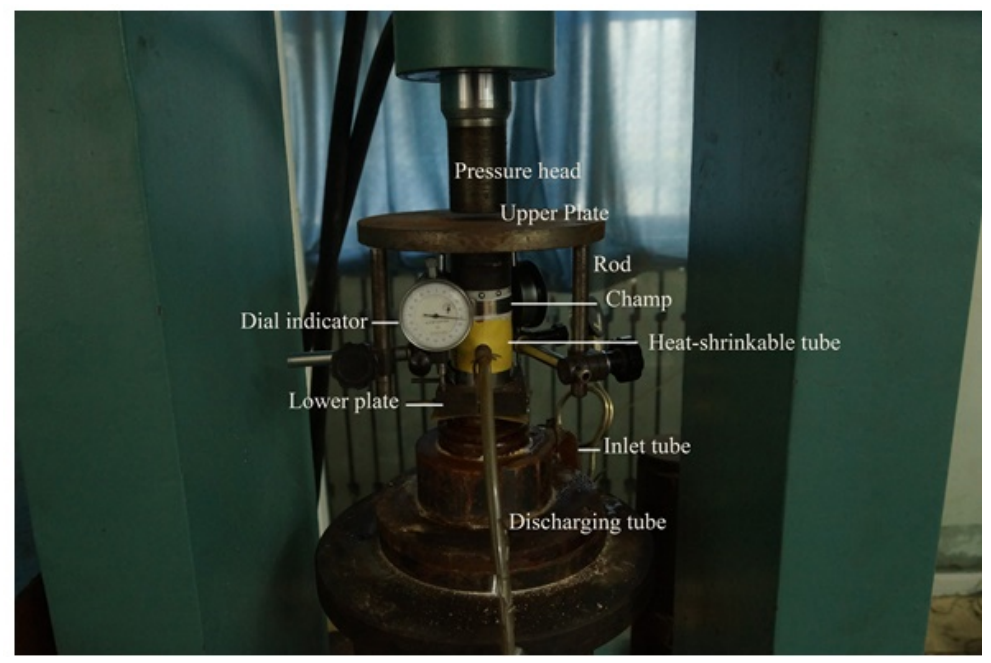

Fig. (4). The self-developed radial flowing system.

By using self-developed radial flowing system (see Fig. 4), the tests of water flowing through a rock joint under different normal stress and different head were carried out at room temperature of $15^{\circ} \mathrm{C}$. The feeding water head were 
set to $22 \mathrm{~m}, 17 \mathrm{~m}, 12 \mathrm{~m}, 7 \mathrm{~m}$ respectively, and normal stress ranged from $1 \mathrm{MPa}$ to $6 \mathrm{MPa}$ with interval of $1 \mathrm{MPa}$ under each feeding water head.

\section{RESULTS}

\subsection{The Relationship Between Flow Rate Per Head and Normal Stress}

Relationships between flow rate per head and normal stress for different feeding water head are shown in Fig. (5). From Fig. (5) we can see that the flow rate per head decreases with the increase of normal stress under the four constant water heads. In this respect, Develi and Babadagli [15] found that decreasing trend of transmissivity occurs with increasing normal load in both injection direction after analysis of single-phase flow through rough fracture replicas. In this test, The relationship between flow rate per head and normal stress is well fitted with the negative exponential function; that is, the decreasing rate of flow rate per head decreases with the increase of normal stress. The formula of flow rate per head and normal stress can be expressed as follow:

$$
\frac{Q}{\Delta H}=P_{1} e^{P_{2} \sigma_{\mathrm{n}}}
$$

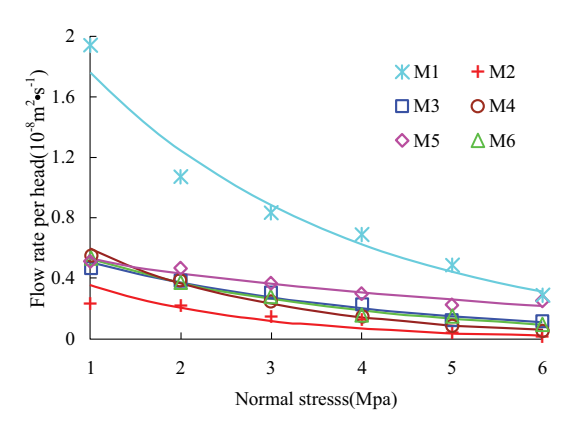

(a) $\Delta H=22 \mathrm{~m}$

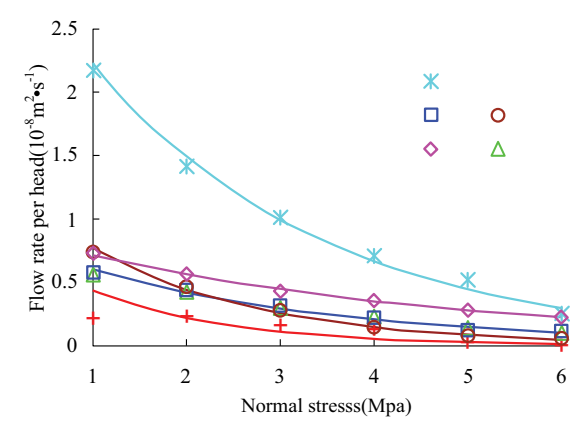

(c) $\Delta H=12 \mathrm{~m}$

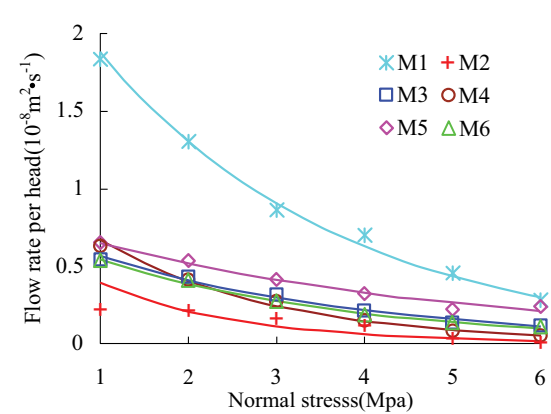

(b) $\Delta H=17 \mathrm{~m}$

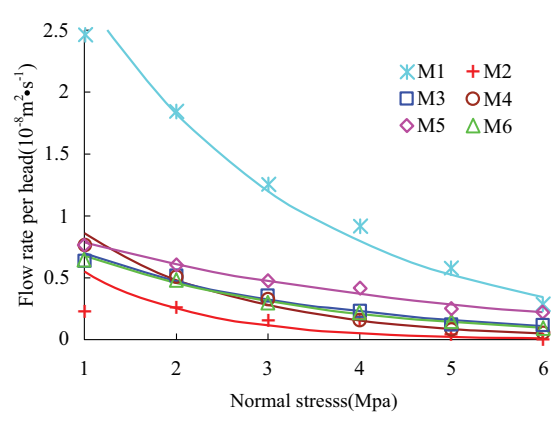

(d) $\Delta H=7 \mathrm{~m}$

Fig. (5). Relationships between flow rate per head and normal stress.

where $Q$ is the flow rate, $\mathrm{m}^{3} \mathrm{~s}^{-1} ; \Delta H$ is the water head difference, $\mathrm{m} ; P_{1}$ and $P_{2}$ are regression parameters, the units are $\mathrm{m}^{2} \mathrm{~s}^{-1}$ and $\mathrm{MPa}^{-1}$ respectively; $\sigma_{\mathrm{n}}$ is the normal stress, MPa. The regression parameters and the correlation coefficients are shown in Table 3 , in which the fitting correlation coefficients $\mathrm{R}^{2}$ are all above 0.70 .

Table 3. Regression parameters and correlation coefficients of Equation (4).

\begin{tabular}{|c|c|c|c|c|c|c|c|c|c|c|c|c|}
\hline \multirow[t]{2}{*}{ No. } & \multicolumn{3}{|c|}{$\Delta H=22 \mathrm{~m}$} & \multicolumn{3}{|c|}{$\Delta H=17 \mathrm{~m}$} & \multicolumn{3}{|c|}{$\Delta H=12 \mathrm{~m}$} & \multicolumn{3}{|c|}{ (d) $\Delta H=7 \mathrm{~m}$} \\
\hline & $P_{1}$ & $P_{2}$ & $\mathbf{R}^{2}$ & $P_{1}$ & $P_{2}$ & $\overline{\mathbf{R}^{2}}$ & $P_{1}$ & $P_{2}$ & $\mathbf{R}^{2}$ & $P_{1}$ & $P_{2}$ & $\overline{\mathbf{R}^{2}}$ \\
\hline M1 & 2.49 & -0.35 & 0.97 & 2.71 & -0.37 & 0.99 & 3.30 & -0.40 & 0.98 & 4.21 & -0.42 & 0.97 \\
\hline M2 & 0.61 & -0.54 & 0.87 & 0.73 & -0.62 & 0.83 & 0.87 & -0.68 & 0.78 & 1.20 & -0.79 & 0.70 \\
\hline M3 & 0.68 & -0.30 & 0.96 & 0.78 & -0.32 & 0.98 & 0.85 & -0.35 & 0.98 & 1.01 & -0.38 & 0.96 \\
\hline M4 & 0.95 & -0.47 & 0.99 & 1.11 & -0.50 & 0.99 & 1.34 & -0.54 & 0.99 & 1.50 & -0.56 & 0.99 \\
\hline M5 & 0.62 & -0.18 & 0.92 & 0.81 & -0.23 & 0.95 & 0.90 & -0.23 & 0.99 & 1.01 & -0.25 & 0.97 \\
\hline M6 & 0.74 & -0.35 & 0.98 & 0.77 & -0.34 & 0.99 & 0.84 & -0.35 & 0.99 & 0.99 & -0.39 & 0.99 \\
\hline
\end{tabular}


The relationships between $P_{1}$ and the maximum of root mean square slope $\left(\mathrm{S}_{\mathrm{dq}}\right)_{\max }$ are shown in Fig. (6) and the relationship between $P_{2}$ and the minimum of peak height on the surface $\left(\mathrm{S}_{\mathrm{p}}\right)_{\min }$ is shown in Fig. (7). As shown in Fig. (6), $P_{1}$ has a logarithmic function relationship with $\left(\mathrm{S}_{\mathrm{dq}}\right)_{\max }$ and $P_{1}$ increases with the increase of the maximum of root mean square slope $\left(\mathrm{S}_{\mathrm{dq}}\right)_{\max }$, and the correlation coefficient $\mathrm{R}^{2}$ is 0.84 . According to the empirical formula of JRC and the slope root mean square proposed by Yang et al., [16], the greater the slope root mean square is, the rougher the joint surfaces is, thus $P_{1}$ is positively related to the roughness of joint surface; when the other parameters are constant in formula (4), the flow rate per head increases with the increase of $\left(\mathrm{S}_{\mathrm{dq}}\right)_{\max }$. In Fig. (7), $P_{2}$ decreases with the increase of the minimum of peak height $\left(\mathrm{S}_{\mathrm{p}}\right)_{\min }$ and there is an logarithmic function relationship between $P_{2}$ and $\left(\mathrm{S}_{\mathrm{p}}\right)_{\min }$, and as $\left(\mathrm{S}_{\mathrm{p}}\right)_{\min }$ of specimen M2 has an obvious dispersion, the fitting correlation coefficient $\mathrm{R}^{2}$ is only 0.69 ; on the whole, when the other parameters are constant in formula (4), the flow rate per head decreases with the increase of $\left(\mathrm{S}_{\mathrm{p}}\right)_{\min }$.

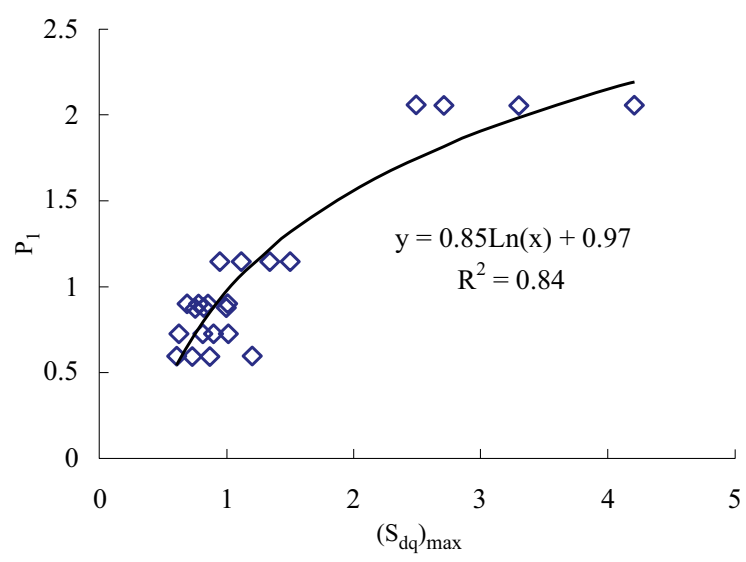

Fig. (6). Relationship between $P_{1}$ and $\left(S_{d q}\right)_{\max }$.

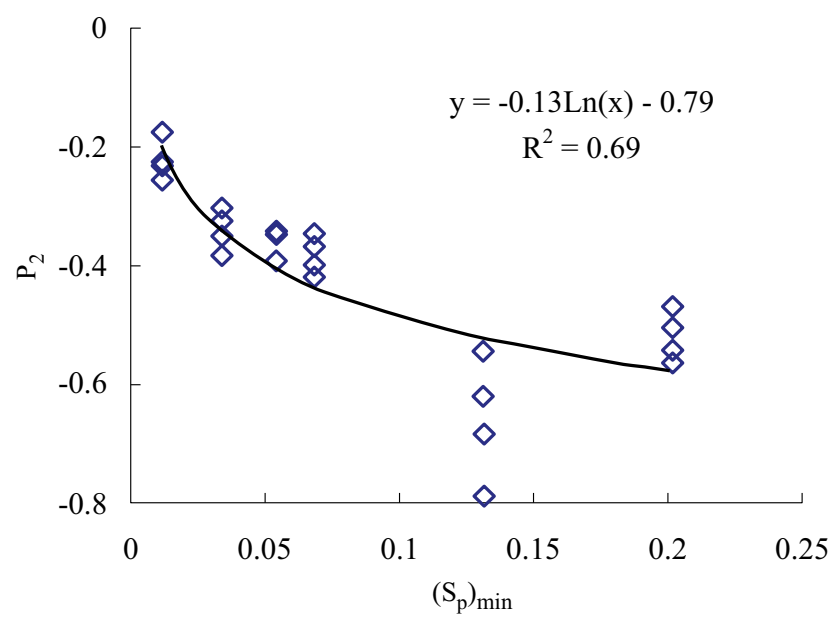

Fig. (7). Relationship between $\mathrm{P}_{2}$ and $(\mathrm{Sp})_{\min }$.

\subsection{The Relationship Between Equivalent Hydraulic Aperture and Mechanical Aperture}

The relationship between equivalent hydraulic aperture and mechanical aperture are shown in Fig. (8). Equivalent hydraulic aperture is obtained based on the formula of the cubic law, and the mechanical aperture is calculated by subtracting the joint closure under different normal stress from the joint closure under the maximum normal stress. As shown in Fig. (8), the equivalent hydraulic aperture increases with the increase of mechanical aperture, there is a linear correlation between equivalent hydraulic aperture and mechanical aperture, and then the relationship between equivalent hydraulic aperture and mechanical aperture can be expressed as:

$$
b_{h}=P_{3} b_{m}+P_{4}
$$


Where $P_{3}$ and $P_{4}$ are regression parameters, in which $P_{3}$ expresses the slope of the straight line and $P_{4}$ expresses yintercept on the vertical axis, and whose value is equal to the initial equivalent hydraulic aperture under the maximum normal stress. Equation (5) is similar to that proposed by Witherspoon et al., [10]. The regression parameters and the correlation coefficients are shown in Table $\mathbf{4}$, and the correlation coefficients are all above 0.93 .

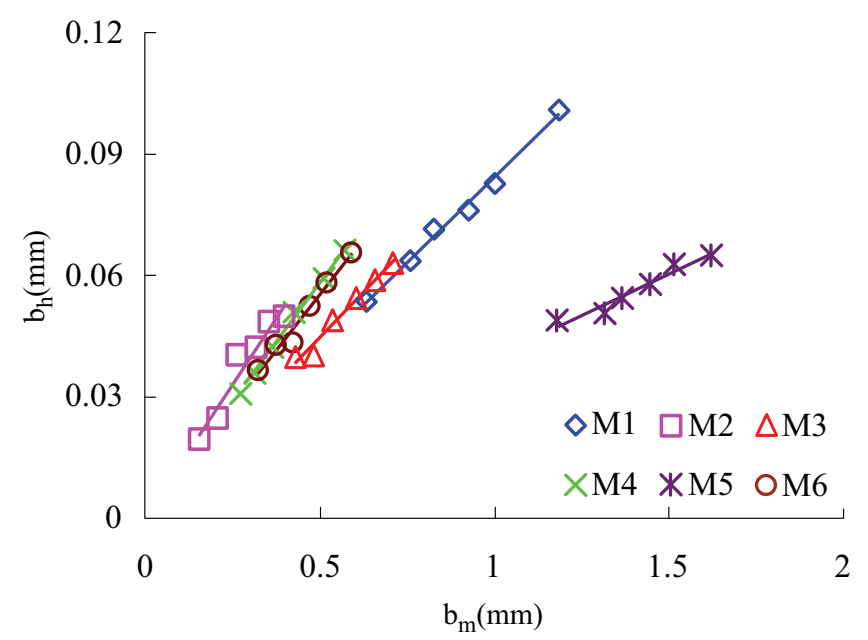

Fig. (8). Relationship between $b_{h}$ and $b_{m}$.

Table 4. Regression parameters and correlation coefficients of Equation (5).

\begin{tabular}{|c|c|c|c|}
\hline No. & $\boldsymbol{P}_{\mathbf{3}}$ & $\boldsymbol{P}_{\mathbf{4}} \times \mathbf{1 0}^{\mathbf{5}}$ & $\mathbf{R}^{\mathbf{2}}$ \\
\hline M1 & 0.08 & -4 & 0.99 \\
\hline M2 & 0.13 & -10 & 0.94 \\
\hline M3 & 0.09 & 9 & 0.98 \\
\hline M4 & 0.12 & 7 & 1.00 \\
\hline M5 & 0.04 & -3 & 0.95 \\
\hline M6 & 0.11 & 5 & 0.98 \\
\hline
\end{tabular}

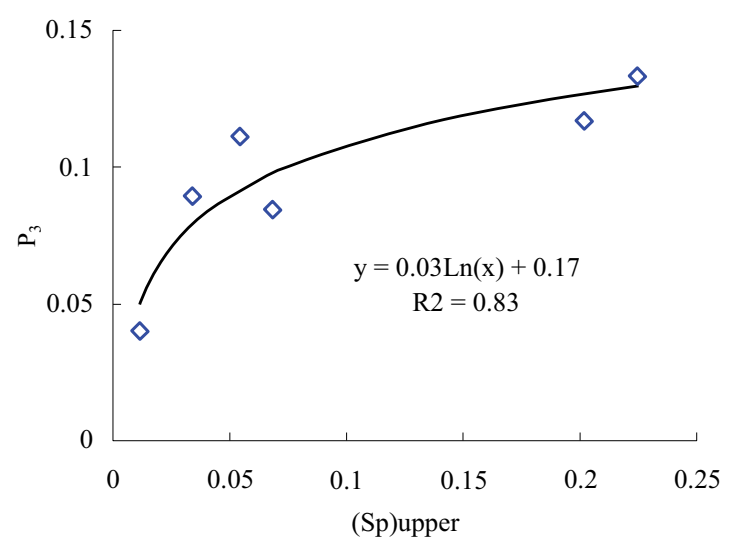

Fig. (9). Correlation between $\mathrm{P}_{3}$ and $\left(\mathrm{S}_{\mathrm{p}}\right)_{\text {upper }}$.

The relationship between $P_{3}$ and $\left(\mathrm{S}_{\mathrm{p}}\right)_{\mathrm{upper}}$ is shown in Fig. (9), and the relationship between $P_{4}$ and $\left(\mathrm{S}_{\mathrm{ds}}\right)_{\text {lower }}$ is shown in Fig. (10). According to the reference [9], the slope of the straight line $P_{3}$ is related to the roughness of joint surface, and the value tends to be a constant for smooth parallel plate. From Fig. (9) we can see that $P_{3}$ rises with increase of the maximal peak height of upper joint surface $\left(\mathrm{S}_{\mathrm{p}}\right)_{\text {upper }}$; there is a logarithmic function between $P_{3}$ and $\left(\mathrm{S}_{\mathrm{p}}\right)_{\text {upper }}$ where the fitting correlation coefficient $\mathrm{R}^{2}$ is 0.83 ; thus, the equivalent hydraulic aperture is positively related to $\left(\mathrm{S}_{\mathrm{p}}\right)_{\text {upper }}$ and $\left(\mathrm{S}_{\mathrm{p}}\right)_{\text {upper }}$ reflects the increasing rate of the equivalent hydraulic aperture with mechanical aperture. As shown in Fig. (10), $P_{4}$ increases with the increase of the peak average density $\left(\mathrm{S}_{\mathrm{ds}}\right)_{\text {lower }}$, and there is a logarithmic function between $P_{4}$ and 
$\left(\mathrm{S}_{\mathrm{ds}}\right)_{\text {lower }}$, where fitting correlation coefficient $\mathrm{R}^{2}$ is 0.95 ; the bigger the $\left(\mathrm{S}_{\mathrm{ds}}\right)_{\text {lower }}$ is, the bigger the initial equivalent hydraulic aperture is.

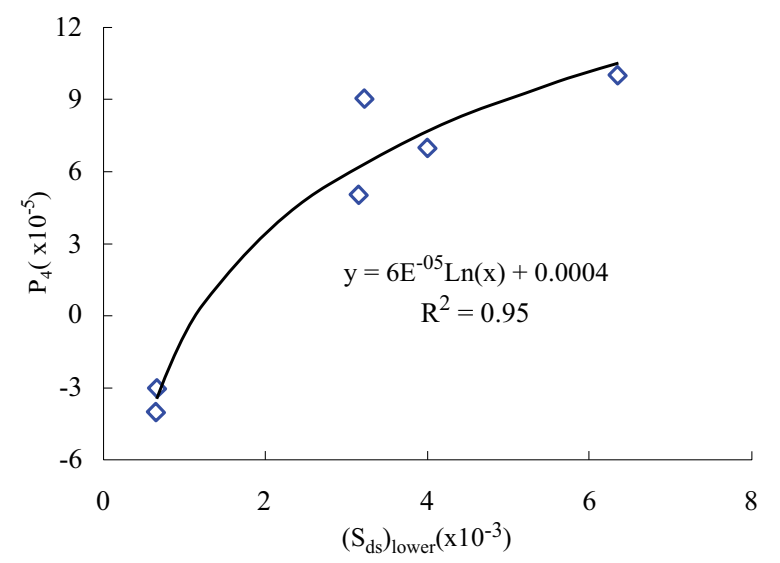

Fig. (10). Correlation between $\mathrm{P}_{4}$ and $\left(\mathrm{S}_{\mathrm{ds}}\right)_{\text {lower }}$.

\subsection{Relationship Between Joint Closure and Normal Stress}

The joint closure is obtained by using the average value of three dial indicator readings under different normal stress. The relationship between joint closure and normal stress is shown in Fig. (11). From that we can see that the joint closure increases with the increase of normal stress, and there is a positive linear relationship between joint closure and normal stress, which is consistent with the results obtained by Giwelli et al., [17], that is:

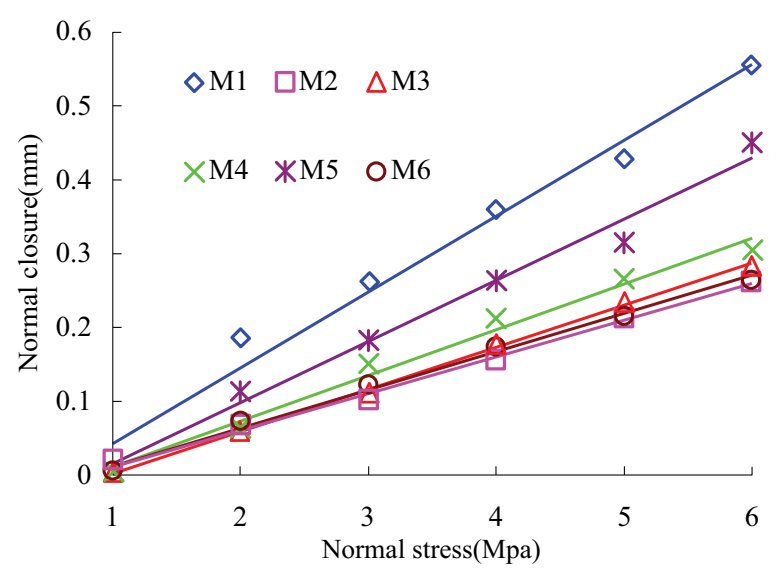

Fig. (11). Relationship between joint closure and normal stress.

$$
\Delta b=P_{5} \sigma_{n}+P_{6}
$$

where $\Delta \mathrm{b}$ is the joint closure, $P_{5}$ and $P_{6}$ are regression parameters, in which $P_{5}$ reflects the change rate of the joint closure, $P_{6}$ is equal to the initial normal closure under zero normal stress, thus $P_{6}$ should be zero generally. The regression parameters and correlation coefficients are shown in Table 5, and the correlation coefficients are all above 0.97 ; as the normal stress ranges from $1 \mathrm{MPa}$ to $6 \mathrm{MPa}$, there is mainly the linear compression deformation of joint with the increase of normal stress.

Table 5. Regression parameters and correlation coefficients of Equation (6).

\begin{tabular}{|c|c|c|c|}
\hline No. & $\boldsymbol{P}_{\mathbf{5}}$ & $\boldsymbol{P}_{\mathbf{6}}$ & $\mathbf{R}^{\mathbf{2}}$ \\
\hline M1 & 0.10 & -0.06 & 0.98 \\
\hline M2 & 0.05 & -0.03 & 0.99 \\
\hline M3 & 0.06 & -0.05 & 1.00 \\
\hline
\end{tabular}




\begin{tabular}{|} 
(Table 5) contd..... \\
\hline No. & $\boldsymbol{P}_{\mathbf{5}}$ & $\boldsymbol{P}_{\mathbf{6}}$ & $\mathbf{R}^{\mathbf{2}}$ \\
\hline M4 & 0.06 & -0.05 & 0.99 \\
\hline M5 & 0.08 & -0.07 & 0.99 \\
\hline M6 & 0.05 & -0.04 & 1.00 \\
\hline
\end{tabular}

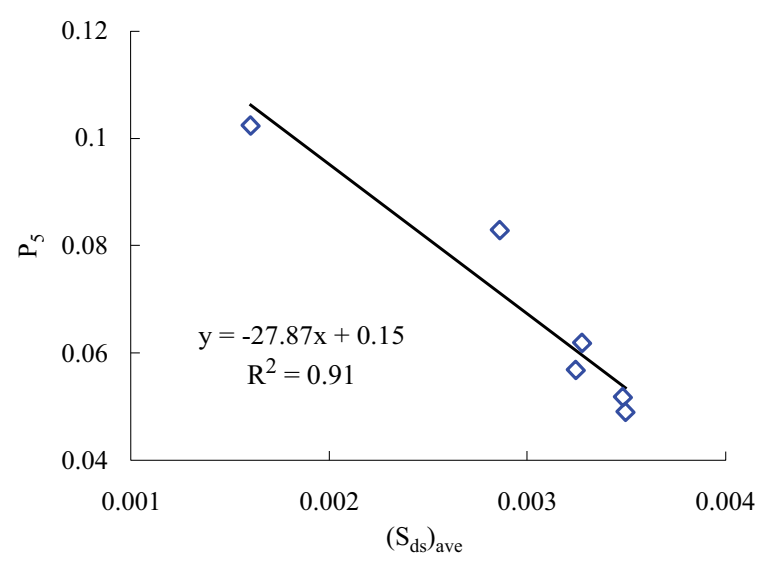

Fig. (12). Relationship between $P_{5}$ and $\left(S_{d s}\right)_{\text {ave }}$.

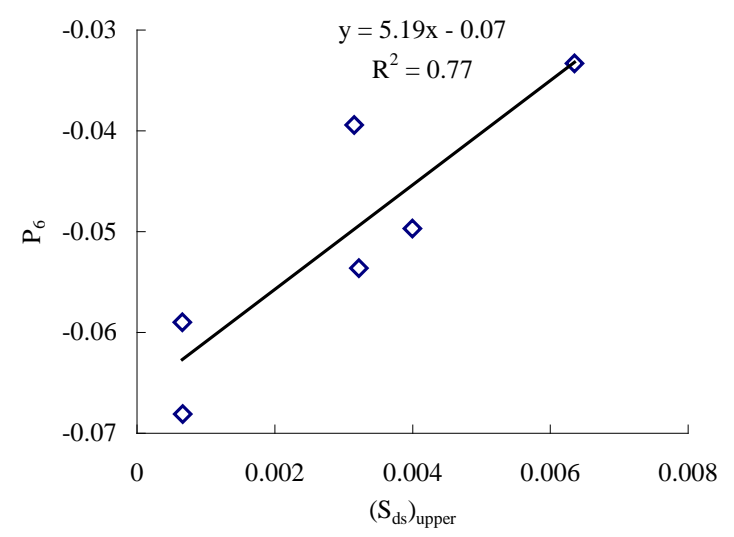

Fig. (13). Relationship between $\mathrm{P}_{6}$ and $\left(\mathrm{S}_{\mathrm{ds}}\right)_{\mathrm{upper}}$.

The relationship between $P_{5}$ and $\left(\mathrm{S}_{\mathrm{ds}}\right)_{\text {ave }}$ is shown in Fig. (12), and the relationship between $P_{6}$ and $\left(\mathrm{S}_{\mathrm{ds}}\right)_{\text {upper }}$ is shown in Fig. (13). As shown in Fig. (12), $P_{5}$ decreases linearly with the increase of $\left(\mathrm{S}_{\mathrm{ds}}\right)_{\mathrm{ave}}$, and it is the negative linear correlation between $P_{5}$ and $\left(\mathrm{S}_{\mathrm{ds}}\right)_{\text {ave }}$ approximately, where the fitting coefficient $\mathrm{R}^{2}$ is 0.91 ; thus the larger $\left(\mathrm{S}_{\mathrm{ds}}\right)_{\text {ave }}$ is, the smaller the joint closure is. From Fig. (13) we can see that $P_{6}$ increases approximately with the increase of the average peak density $\left(\mathrm{S}_{\mathrm{ds}}\right)_{\mathrm{upper}}$; and it is the positive linear correlation between $P_{6}$ and $\left(\mathrm{S}_{\mathrm{ds}}\right)_{\text {upper }}$ where the fitting coefficient $\mathrm{R}^{2}$ is 0.77; thus, initial joint closure with zero normal stress increases with the increase of $\left(\mathrm{S}_{\mathrm{ds}}\right)_{\text {upper }}$. Besides, as a result of the existence of experimental error, $P_{6}$ is not always equal to zero.

\section{DISCUSSIONS AND CONCLUSION}

The splitting coarse-grained marble joint surfaces were scanned by Tianyuan OKIO-typed three-dimensional laser scanner, and then, the tests of water flowing through a single rock joint are carried out by using the self-developed radial flow system; finally, the relationship between the seepage and mechanical characteristics of rock joint and 3D morphology parameters of joint surfaces are studied. As the tests results, the exponential function between flow rate per head and normal stress, the linear relation between equivalent hydraulic aperture and mechanical aperture, and the linear relation between joint closure and normal stress are found. By analysis of the relationship between the seepage and mechanical characteristics of rock joint and 3D morphology parameters, it is also found that there are close relationships between some 3D morphology parameters of joint surfaces and the regression parameters in equations that express the seepage and mechanical characteristics of rock joint. 
The relationship between hydraulic conductivity of rock joint and normal stress without regard to joint roughness is convenient for application, but it can also cause a large error. It can expand the application scope of the formula when regression parameters in the relationship are expressed with morphology parameters of rock joint. Although it is proved that the cubic law is not applicable to rough rock joint, the linear relationship between equivalent hydraulic aperture and mechanical aperture means that the cubic law is applicable in this experiment. Usually, there is a hyperbolic relationship between joint closure and normal stress, but because of a relative small range of normal stress and lack of test data below $1 \mathrm{MPa}$, the linear relationship between joint closure and normal stress seems to be acceptable. In the future, test studies on hydraulic conductivity of rock joint in larger ranges of rock type, joint size, normal stress, and water head should be conducted to master the general law of seepage of rock joint including its size effect. The flow rate of rock joint can be obtained under the condition that the normal stress is known if the morphology parameters could be determined in numerical simulation, which is more credible than simple application of cubic law.

Specifically, the main conclusions are as follows:

1. The relationship between flow rate per head and normal stress is well fitted with a negatively exponential function, and the flow rate per head decreases with increase of normal stress; the regression parameter $P_{l}$ has a logarithmic relation with $\left(\mathrm{S}_{\mathrm{dq}}\right)_{\max }$ and increases with the increase of $\left(\mathrm{S}_{\mathrm{dq}}\right)_{\max }$, while the regression parameter $P_{2}$ has a logarithmic function relationship with $\left(\mathrm{S}_{\mathrm{p}}\right)_{\min }$ and decreases with the increase of $\left(\mathrm{S}_{\mathrm{p}}\right)_{\min }$.

2. The equivalent hydraulic aperture has a linear relation with the mechanical aperture and increases with the increase of mechanical aperture; it is a logarithmic function relationship between the regression parameter $P_{3}$ and $\left(\mathrm{S}_{\mathrm{p}}\right)_{\text {upper }}$ and $P_{3}$ increases with increase of $\left(\mathrm{S}_{\mathrm{p}}\right)_{\text {upper }}$; while, it is a logarithmic function relationship between the regression parameter $P_{4}$ and $\left(\mathrm{S}_{\mathrm{ds}}\right)_{\text {lower }}$ and $P_{4}$ increases with the increase of the $\left(\mathrm{S}_{\mathrm{ds}}\right)_{\text {lower }}$.

3. There is a positively linear relationship between joint closure and normal stress and the joint closure increases with the increase of normal stress; there is a negatively linear relationship between the regression parameter $P_{5}$ and $\left(\mathrm{S}_{\mathrm{d}}\right)_{\text {ave }}$ and $P_{5}$ decreases with the increase of $\left(\mathrm{S}_{\mathrm{ds}}\right)_{\text {ave }}$; while, there is a the linear relationship between the regression parameter $\mathrm{p}_{6}$ and $\left(\mathrm{S}_{\mathrm{ds}}\right)_{\mathrm{upper}}$ and $P_{6}$ increases with the increase of $\left(\mathrm{S}_{\mathrm{ds}}\right)_{\mathrm{upper}}$.

\section{CONFLICT OF INTEREST}

The authors confirm that this article content has no conflict of interest.

\section{ACKNOWLEDGEMENTS}

This research is supported by the China National Natural Science Foundation (Project Nos. 51109076) and the key scientific and technological project of Henan Province (152102210316).

\section{REFERENCES}

[1] R.L. Kranz, A.D. Frankel, and T. Engelder, "The permeability of whole and jointed Barre granite", Int. J. Rock Mech. Min. Sci. Geomech. Abstr., vol. 16, pp. 225-234, 1979. [http://dx.doi.org/10.1016/0148-9062(79)91197-5]

[2] G.P. Li, and Z.Y. Tao, "Research on the law of seepage of a single fracture under normal stress", J. Wuhan Univ. Hydr. \& Elec. Eng., vol. 26, pp. 168-173, 1993.

[3] B.Y. Su, M.L. Zhan, and Y. Wang, "Experimental study on coupling characteristics of fluid flow and stress within fracture", Chin. J. Geotech. Eng., vol. 19, pp. 73-77, 1997.

[4] C. Louis, Rock Hydraulics in rock mechanics., Springer-Verlag: New York, 1974.

[5] F.O. Jones, "A laboratory study of the effects of confining pressure on fracture flow and storage capacity in carbonate rocks", J. Pet. Technol., vol. 21 , pp. 21-27, 1975 .

[http://dx.doi.org/10.2118/4569-PA]

[6] R.A. Nelson, "Fracture permeability in porous reservoirs: an experimental and field approach", Ph.D. thesis. Texas A\&M University, Austin, TX, USA 1975.

[7] J.E. Gale, "The effects of fracture type(induced versus natural) on the stress, fracture closure, fracture permeability relationship", In: Proc. 23rd. Rock. Mech. Conf., AIME: Berkeley, USA, 1982, pp. 290-298.

[8] G.M. Elliot, E.T. Brown, and P.I. Boodt, "Hydromechanical behaviour of the Carnmenellis granite, S.W.England", In: Proc. Int. Conf. on Fundamentals of Rock Joints, Björkliden, Sweden, 1985, pp. 249-258.

[9] N. Barton, S. Bandis, and K. Bakhtar, "Strength, deformation and conductivity coupling of rock joints", Int. J. Rock Mech. Min. Sci. 
Geomech. Abstr., vol. 22, pp. 121-140, 1985, .

[http://dx.doi.org/10.1016/0148-9062(85)93227-9]

[10] P.A. Witherspoon, C.H. Amick, and J.E. Gale, "Observations of potential size effect in experimental determination of the hydraulic properties of fractures", Water Resour. Res., vol. 15, pp. 1142-1146, 1979. [http://dx.doi.org/10.1029/WR015i005p01142]

[11] R.W. Zimmerman, and G.S. Bodvarsson, "Hydraulic conductivity of rock fractures", Transp. Porous Media, vol. 23, pp. 1-30, 1996. [http://dx.doi.org/10.1007/BF00145263]

[12] E. Hakami, "Aperture distribution of rock fractures", PhD thesis. Royal Institute of Technology, Stockholm, Sweden 1995

[13] G.Z. Sun, and W.Z. Lin, "The law of structural plane closed deformation and the elastic constitutive equation of rock mass", Chin. J. Geol., vol. 2, pp. 81-87, 1983 .

[14] R.E. Goodman, Geological engineering method for discontinuous rock mass., China Railway Publishing House: Beijing, 1983.

[15] K. Develi, and T. Babadagli, "Experimental and visual analysis of single-phase flow through rough fracture replicas", Int. J. Rock Mech. Min. Sci., vol. 73, pp. 139-155, 2015.

[http://dx.doi.org/10.1016/j.ijrmms.2014.11.002]

[16] Z.Y. Yang, S.C. Lo, and C.C. Di, "Reassessing the joint roughness coefficient (JRC) estimation using Z2", Rock Mech. Rock Eng., vol. 24, pp. 243-251, 2001. [http://dx.doi.org/10.1007/s006030170012]

[17] A.A. Giwelli, K. Sakaguchi, and K. Matsuki, "Experimental study of the effect of fracture size on closure behavior of a tensile fracture under normal stress", Int. J. Rock Mech. Min. Sci., vol. 46, pp. 462-470, 2009. [http://dx.doi.org/10.1016/j.ijrmms.2008.11.008]

(C) Wang et al.; Licensee Bentham Open

This is an open access article licensed under the terms of the Creative Commons Attribution-Non-Commercial 4.0 International Public License (CC BY-NC 4.0) (https://creativecommons.org/licenses/by-nc/4.0/legalcode), which permits unrestricted, non-commercial use, distribution and reproduction in any medium, provided the work is properly cited. 